\title{
Impact of metabolic syndrome and clinical features on functioning in patients with bipolar disorder: a cross-sectional study
}

\author{
Hanife Kocakaya, ${ }^{1}$ (iD Emrah Songur, ${ }^{2}$ Sedat Batmaz, ${ }^{3}$ (iD Zekiye Çelikbaş, ${ }^{3}$ Önder Küçük ${ }^{1}$ \\ ${ }^{1}$ Dr. Cevdet Aykan Mental Health and Diseases Hospital, Tokat, Turkey. ${ }^{2}$ Keçiören Education and Research Hospital, Ankara, Turkey. \\ ${ }^{3}$ Gaziosmanpaşa University Faculty of Medicine, Tokat, Turkey.
}

\begin{abstract}
Objective: The metabolic syndrome (MS) is highly prevalent among patients with bipolar disorder (BD), and may affect progression, functioning, and comorbid conditions in BD. The aim of this study was to investigate the effect of clinical variables and MS on overall functioning and specific areas of functioning in patients with BD.

Methods: A total of 210 participants (140 participants with BD I and BD II in remission and 70 nonpsychiatric control subjects) were included. The investigators administered the Young Mania Rating Scale (YMRS), the Bipolar Depression Rating Scale (BDRS), the Global Assessment of Functioning Scale (GAF), and the Bipolar Disorder Functioning Scale (BDFS). The participants completed the Beck Depression Scale (BDS) and the Beck Anxiety Scale (BAS). MS was diagnosed according to the National Cholesterol Education Program Adult Treatment Panel III (NCEP ATP III) criteria. Hierarchical regression analysis was used to investigate potential correlations of comorbid MS with clinical variables and level of functioning.

Results: Level of functioning did not differ between patients with and without MS. However, there were significant correlations between the level of functioning subscales and the number of depressive episodes $(p=0.033)$, level of general functioning $(p=0.012)$, duration of illness $(p=0.012)$, BDS $(p=0.005)$, BDRS $(p=0.021)$, BAS total scores $(p=0.021)$, number of hypomanic episodes $(p=0.022)$, number of hospitalizations $(p=0.003)$, employment status $(p=0.032)$, and diagnosis of BD I $(p=0.007)$ and BD II $(p=0.044)$.

Conclusion: Our findings suggest that clinical variables had a greater effect on functioning than MS in BD patients.
\end{abstract}

Keywords: Bipolar disorder; clinical factors; functionality; metabolic syndrome

\section{Introduction}

Bipolar disorder (BD) is a chronic disorder that consists of recurrent depressive, manic, hypomanic episodes, or mood episodes with mixed features leading to severe social and occupational functional loss. It is ranked sixth among the leading causes of disability in the world. ${ }^{1}$ Furthermore, the long-term use of antipsychotics (AP) or mood stabilizers for its treatment, coupled with the unhealthy impact of exacerbations, is associated with untoward effects. ${ }^{2}$ Several lifestyle factors common in patients with $\mathrm{BD}$ - such as high calorie dietary intake, smoking, and physical inactivity - are associated with an increased risk for obesity, dyslipidemia, diabetes mellitus, and the metabolic syndrome (MS). ${ }^{3} \mathrm{MS}$ is characterized by the clustering of several metabolic abnormalities: abdominal obesity, dyslipidemia, hyperinsulinemia, impaired fasting glucose, and high blood pressure. ${ }^{4}$ The prevalence of

Correspondence: Hanife Kocakaya, Dr. Cevdet Aykan Mental Health and Diseases Hospital, Perakende District, Center Merkez, 60100, Tokat, Turkey.

E-mail: drhanifekocakaya @gmail.com

Submitted Jul 24 2019, accepted Nov 20 2019, Epub Mar 162020.
MS in BD ranges from 17 to $53 \%$, and is 1.6 times higher than in the general population. ${ }^{5}$

Functioning is known as a complex concept that encompasses working capacity, independent living, social activities, and interpersonal relationships. ${ }^{6} \mathrm{BD}$ can lead to serious disturbances in family relationships, social life, and functioning, due to its natural history characterized by alternating periods of illness and well-being, as well as to the need for long-term treatment. ${ }^{7}$ It is known that a significant proportion of patients with BD continue to experience subsyndromal symptoms, and that they spend much of their lives symptomatically despite psychopharmacological treatment. ${ }^{8}$ In a prospective study in which patients with $\mathrm{BD}$ experiencing their first manic episode were followed up for 2 years, the symptomatic recovery rate was reported to be $72 \%$, while the functional recovery rate was only $43 \% .{ }^{9}$ In another study, at 6-month follow-up, symptomatic outcome was clearly superior to
How to cite this article: Kocakaya $\mathrm{H}$, Songur $\mathrm{E}$, Batmaz $\mathrm{S}$, Çelikbaş Z, Küçük Ö. Impact of metabolic syndrome and clinical features on functioning in patients with bipolar disorder: a crosssectional study. 2020;42:373-381. http://dx.doi.org/10.1590/15164446-2019-0622 
functional outcome. While nearly $80 \%$ of patients were asymptomatic or mildly symptomatic, only $43 \%$ were able to work, and only $21 \%$ of those able to work could meet the expected level of functioning. ${ }^{10}$ In addition, the presence of MS in these cases may lead to increased risk of suicide, decreased functioning, and exacerbated clinical manidestations. ${ }^{5}$ Similarly, Calkin et al. reported that $39.1 \%$ of 276 patients with BD were obese, and that these patients had a longer duration of illness, poorer global function, and more disability. ${ }^{11}$ In a study evaluating the effects of MS-related lifestyle factors on quality of life and functioning in patients with $\mathrm{BD}$ and schizophrenia, no difference was noted in terms of the level of functioning assessed by the Global Assessment of Functioning (GAF) scale. ${ }^{12}$

In this study, we aimed to assess the levels of overall functioning and specific areas of functioning in a remitted BD population using a comprehensive scale, and to investigate the effect of MS and clinical features on functioning in these patients.

\section{Methods}

\section{Participants}

The study was carried out between March and July 2016 on 140 patients who had received a diagnosis of BD according to the DSM-5 diagnostic criteria and 70 healthy controls. ${ }^{13}$ BD patients were randomly selected among those who received regular follow-up at a psychiatry clinic. The inclusion criteria were: i) diagnosis of $\mathrm{BD}$ I or BD II according to DSM- 5 criteria; ii) age between 18 to 65 years; and iii) euthymia for at least 3 months before entering the study. The exclusion criteria were: i) intellectual disability and/or pervasive developmental disorder; ii) diagnosis of substance and/or alcohol related disorder, or any other comorbid psychiatric disorder. As patients with different BD subtypes showed significant differences in psychotropic medication use due to the nature of the disease, treatment was recorded, but not included in the analysis. The healthy controls consisted of volunteers presenting to the physical therapy and rehabilitation clinic of the hospital. These volunteers were included if they had no history of psychiatric, neurological, and chronic medical diseases. Participants in the control group were not matched by age, sex, or any other variables, but they were recruited to the study in consecutive order of presentation. Verbal and written consent were obtained from all participants.

\section{Materials}

\section{Sociodemographic and clinical data}

The sex, age, marital status, child status (if any), level of education, employment status, and monthly income of the participants were recorded on a specific form.

\section{Bipolar Disorder Functioning Scale (BDFS)}

This scale, which was developed by Aydemir et al., consists of 52 items and 11 subscales (intellectual functioning, sexual functioning, feelings of stigmatization, social withdrawal, household relations, participation in social activities, daily activities and hobbies, taking initiative, and self-sufficiency). The scale has no cutoff points. Higher scores are indicative of increased level of functioning. ${ }^{14}$

\section{Young Mania Rating Scale (YMRS)}

This clinician-rated scale was developed by Young et al. to measure the severity of manic episodes. The scale consists of 11 items, each containing five degrees of severity. ${ }^{15}$

\section{Bipolar Depression Rating Scale (BDRS)}

This is a Likert-type scale consisting of 20 items that is used by the interviewer to assess the severity of depressive symptoms; each item is scored from 0 to 3 . Scores on the BDRS are directly proportional to the severity of the depressive symptoms. ${ }^{16}$ The reliability and validity of this scale were reported by Batmaz et al. ${ }^{17}$

\section{Beck Anxiety Scale (BAS)}

This self-report scale measures the prevalence of anxiety symptoms experienced by an individual. High scores indicate that the severity of the anxiety experienced by the individual is burdensome. ${ }^{18}$ The validity and reliability of the Turkish version were demonstrated by Ulusoy et al. ${ }^{19}$

\section{Beck Depression Scale (BDS)}

This self-report scale was developed to assess the severity of depressive symptoms. Each item is scored from 0 to 3; the total score varies between $0-63 .^{20}$ The cutoff score of the Turkish version of the scale is $17 .^{21}$

\section{Global Assessment of Functioning Scale (GAF)}

This measure helps monitor the clinical course of patients. This clinician-graded scale is evaluated by scoring the patient's function on a score of 1 to 100 for a given time interval or period. ${ }^{22}$

\section{Metabolic syndrome (MS)}

The presence of MS was determined according to the National Cholesterol Education Program Adult Treatment Panel III (NCEP ATP III) diagnostic criteria. ${ }^{23}$ Body weight, height, and waist circumference were measured. In addition, laboratory findings (fasting blood glucose, HDL-cholesterol, LDL-cholesterol, triglycerides) and blood pressure values were recorded for all groups.

\section{Statistical analysis}

In the study, quantitative variables were presented as mean and standard deviation, and qualitative variables as absolute and relative frequency. The difference between means of the quantitative variables was tested by an independent-samples $t$-test and by one-way analysis of variance (ANOVA). Since this study was exploratory, no correction for multiple testing was performed. Hierarchical linear regression analyses were used to evaluate the 
proposed relationships between comorbid MS, clinical variables, and level of functioning. In addition, the relationships between the parameters were examined by Pearson correlation analysis. P-values were considered statistically significant if $<0.05$.

\section{Ethics statement}

This study was approved by the clinical research ethics committee of Tokat Gaziosmanpasa University School of Medicine, Tokat, Turkey (protocol 2016/014).

\section{Results}

A total of 210 participants were included in the study; mean age was $43.51 \pm 11.75$ years for the BD I group, $43.17 \pm 12.97$ years for the BD II group, and $40.83 \pm 10.78$ years for the control group. There was a significant difference among non-psychiatric controls and the other groups in terms of mean age $(p<0.001)$. The number of female participants in the BD II group was significantly higher than in the other groups $(p=0.003)$. Nonpsychiatric controls were more often gainfully employed than participants with BD $(p<0.001)$. The demographic characteristics of the groups were compared with the chi-square test; data are presented in Table 1.

When patients were evaluated according to their clinical features, hospitalization rates were significantly higher in the $\mathrm{BD}$ I group than in the $\mathrm{BD}$ || group $(p<0.001)$, whereas the number of depressive episodes was significantly higher in the BD II group than in the BD I group $(p=0.024)$. There were no statistically significant differences between groups in terms of the age at onset of the disorder $(p=0.429)$. There were no significant differences between the two BD groups regarding YMRS, BDRS, BDS, or BAS scores $(p=0.601$, $p=0.860, p=0.187$, and $p=0.491$, respectively). The clinical characteristics of the groups (compared by ANOVA) are presented in Table 2.

According to the NCEP-ATP III criteria, the prevalence of MS was $57.1 \%$ for the BD I group, $30 \%$ for the BD II group, and $35.7 \%$ for the non-psychiatric controls $(\mathrm{p}<0.003)$.

Bipolar participants with MS ( $n=61)$ were compared to those without MS $(n=79)$ in terms of BDFS and clinical characteristics, but no significant differences were found in subscale and scale values $(p>0.05)$ (Table 3$)$.

The participants' level of functioning was assessed with the BDFS, using a hierarchical linear regression model. The aim of this analysis was to examine whether clinical features and MS had any effect on the functioning of bipolar patients in remission. There was a significant negative correlation between emotional functioning and number of depressive episodes ( $p=0.03$ ), as well as a significant positive correlation between emotional functioning and general functioning levels $(p=0.012)$. Intellectual

Table 1 Demographic and clinical characteristics of the participants

\begin{tabular}{|c|c|c|c|c|c|}
\hline \multirow[b]{2}{*}{ Variables } & \multicolumn{3}{|c|}{ Groups } & \multirow[b]{2}{*}{ Chi-square/F } & \multirow[b]{2}{*}{ p-value } \\
\hline & $\mathrm{BD} I(\mathrm{n}=70)$ & BD II $(n=70)$ & Control $(n=70)$ & & \\
\hline Age (years) & $43.51(11.75)$ & $43.17(12.97)$ & $40.83(10.78)$ & 11.773 & $<0.001$ \\
\hline Sex, female & $33(47.1)$ & $52(74.3)$ & $37(52.9)$ & 11.775 & 0.003 \\
\hline \multicolumn{6}{|l|}{ Marital status } \\
\hline $\begin{array}{l}\text { Single } \\
\text { Married } \\
\text { Divorced } \\
\text { Separated } \\
\text { Widow }\end{array}$ & $\begin{array}{c}15(21.4) \\
46(65.7) \\
7(10) \\
2(2.9) \\
0(0)\end{array}$ & $\begin{array}{c}21(30) \\
34(48.6) \\
6(8.6) \\
3(4.3) \\
6(8.6)\end{array}$ & $\begin{array}{l}9(12.9) \\
56(80) \\
4(5.7) \\
0(0) \\
1(1.4)\end{array}$ & 22.634 & 0.004 \\
\hline \multicolumn{6}{|l|}{ Highest level of education } \\
\hline $\begin{array}{l}\text { Illiterate } \\
\text { Primary education } \\
\text { Secondary education } \\
\text { Higher education }\end{array}$ & $\begin{array}{c}2(2.9) \\
33(47.1) \\
9(12.9) \\
14(20)\end{array}$ & $\begin{array}{c}6(8.6) \\
21(30) \\
10(14.3) \\
13(18.6)\end{array}$ & $\begin{array}{c}1(1.4) \\
21(30) \\
3(4.3) \\
26(37.1)\end{array}$ & 22.420 & 0.013 \\
\hline Income level (TL) & $974.54(1,021.73)$ & $879.71(1,060.74)$ & $1,495.71(951.60)$ & 1.124 & 0.327 \\
\hline Employment status, employed & $29(41.4)$ & $22(31.4)$ & $53(75.7)$ & 30.212 & $<0.001$ \\
\hline \multicolumn{6}{|l|}{ Psychotropic medication use } \\
\hline $\begin{array}{l}\text { MSD or AAP } \\
M S D+A A P \\
M S D+M S D+A A P \\
M S D+T A P+A A P \\
M S D+A A P+A A P \\
M S D+A A P+A D \\
M S D+A D\end{array}$ & $\begin{array}{l}26(37.1) \\
21(30) \\
8(11.4) \\
4(5.7) \\
9(12.9) \\
1(1.4) \\
1(1.4)\end{array}$ & $\begin{array}{c}25(35.7) \\
18(25.7) \\
2(2.9) \\
0(0) \\
3(4.3) \\
8(11.4) \\
14(20)\end{array}$ & $\begin{array}{l}0(0) \\
0(0) \\
0(0) \\
0(0) \\
0(0) \\
0(0) \\
0(0)\end{array}$ & 27.561 & $<0.001$ \\
\hline
\end{tabular}

Data presented as mean (standard deviation) or $n(\%)$.

Results are from one-way analysis of variance (ANOVA) or chi-squared test.

AAP = atypical antipsychotics; AD = antidepressant; BD I = bipolar disorder I; BD II = bipolar disorder II; MSD = mood stabilizer drug;

TAP = typical antipsychotics; TL = Turkish lira. 
Table 2 Clinical characteristics of the participants

\begin{tabular}{|c|c|c|c|c|c|}
\hline & BD I & BD II & $\mathrm{HC}$ & $\mathrm{F} / \mathrm{t}$ & $p$-value \\
\hline Age at first episode (years) & $24.38 \pm 8.81$ & $30.24 \pm 10.46$ & $\mathrm{~N} / \mathrm{A}$ & 0.850 & 0.429 \\
\hline Total number of depressive episodes & $4.94 \pm 2.48$ & $5.49 \pm 2.67$ & N/A & 3.831 & 0.024 \\
\hline Total number of manic episodes & $3 \pm 1.77$ & $\mathrm{~N} / \mathrm{A}$ & N/A & $\mathrm{N} / \mathrm{A}$ & $\mathrm{N} / \mathrm{A}$ \\
\hline Total number of hypomanic episodes & $0.78 \pm 1.48$ & $3.21 \pm 2.19$ & $\mathrm{~N} / \mathrm{A}$ & 0.218 & 0.804 \\
\hline Total number of hospitalizations & $2.77 \pm 1.98$ & $0.49 \pm 0.79$ & N/A & 43.39 & $<0.001$ \\
\hline Bipolar Depression Rating Scale (BDRS) & $3.1 \pm 3.05$ & $3.5 \pm 3.03$ & $\mathrm{~N} / \mathrm{A}$ & 0.151 & 0.860 \\
\hline Young Mania Rating Scale (YMRS) & $0.26 \pm 0.97$ & $0.04 \pm 0.36$ & $\mathrm{~N} / \mathrm{A}$ & 0.510 & 0.601 \\
\hline Beck Depression Scale (BDS) & $4.9 \pm 4.7$ & $6.66 \pm 4.78$ & $6.01 \pm 4.89$ & 1.692 & 0.187 \\
\hline Beck Anxiety Scale (BAS) & $10.1 \pm 7.66$ & $12.73 \pm 6.84$ & $7.44 \pm 6.71$ & 0.714 & 0.491 \\
\hline
\end{tabular}

Results are from one-way analysis of variance (ANOVA) or $t$-test for independent samples.

$\mathrm{BD} \mathrm{I}=$ bipolar disorder I; $\mathrm{BD} \mathrm{II}=$ bipolar disorder II; $\mathrm{HC}=$ healthy control subjects; $\mathrm{N} / \mathrm{A}=$ not available.

Table 3 Comparison of clinical characteristics of bipolar patients with and without MS

\begin{tabular}{lccr}
\hline & MS & Not-MS & $t$ \\
\hline BDFS subscales & & & \\
$\quad$ Emotional functioning & $7.180(1.627)$ & $7.354(1.648)$ & 0.127 \\
Intellectual functioning & $8.934(1.998)$ & $9.113(2.124)$ & 0.604 \\
$\quad$ Sexual functioning & $8.082(2.511)$ & $8.316(2.780)$ & 0.378 \\
Feeling of stigmatization & $8.245(2.501)$ & $8.468(2.605)$ & 0.422 \\
Social withdrawal & $7.442(1.60)$ & $7.253(1.705)$ & 0.68 \\
Household relations & $14.426(3.989)$ & $14.367(3.512)$ & 0.025 \\
Participation to social activities & $10.606(2.685)$ & $11.164(3.240)$ & 2.254 \\
Daily activities and hobbies & $11.819(2.513)$ & $11.443(2.330)$ & 0.981 \\
Taking initiative and self-sufficiency & $5.934(2.197)$ & $5.974(2.207)$ & 0.542 \\
Bipolar Depression Rating Scale (BDRS) & & & 0.875 \\
Beck Depression Scale (BDS) & $2.067(2.811)$ & $2.279(3.015)$ & 0.136 \\
Beck Anxiety Scale (BAS) & $5.775(4.747)$ & $5.940(4.897)$ & 0.463 \\
\hline
\end{tabular}

Data presented as mean (standard deviation).

Results are from a $t$-test for independent samples.

BDFS = Bipolar Disorder Functioning Scale; MS = metabolic syndrome.

functioning correlated positively with duration of illness $(p=$ 0.012 ), but negatively with diagnosis of BD I and number of depressive episodes $(p=0.007$ and $p=0.033$, respectively). Sexual functioning correlated negatively with BDS scores $(p=0.005)$, and positively with number of past hypomanic episodes $(p=0.022)$. There was a significant negative correlation between feeling of stigma and being diagnosed with BD I $(p=0.002)$. Social withdrawal correlated positively with number of hospitalizations $(p=0.017)$, but negatively with BDRS and BAS scores $(p=0.003, p=0.021$, respectively). There was a significant negative correlation between household relations and BDRS scores $(p=0.021)$. Participation in social activities correlated positively with number of hospitalizations and general functioning ( $p=0.039, p<0.001$, respectively), and negatively with number of depressive episodes $(p=0.026$ ). Daily activity and hobbies correlated positively with duration of illness and employment status $(p=0.011$, $p=0.032$, respectively), but negatively with number of depressive episodes and diagnosis of BD II $(p=0.037$, $p=0.044$, respectively). There was a significant positive correlation between initiative taking and working status and general functional level $(p<0.001, p=0.005$, respectively). Total BDFS scores correlated positively with employment status and general functional level $(p=0.037$, $p<0001$, respectively), and negatively with total number of depressive episodes and BAl scores $(p=0.019$, $p=0.014$, respectively). There was no significant correlation of BDFS scores with MS (Tables 4 and 5).

The relationship between MS parameters and BDFS was evaluated by Pearson correlation analysis. There was a weak, significant negative correlation between intellectual functioning and body mass index (correlation coefficient $[r]=-0.166, p=0.017)$, waist circumference $(r=-0.140, p=0.042)$ and systolic blood pressure $(r=$ $-0.172, p=0.012$ ). There was a weak, significant negative correlation between participation in social activities and waist circumference $(r=-0.221, p=0.027)$ and systolic blood pressure $(r=-0.153, p<0.001)$.

\section{Discussion}

In this study, we aimed to assess the levels of overall functioning and specific areas of functioning in a remitted $\mathrm{BD}$ population using a comprehensive scale, as well as to investigate the effect of MS and clinical features on functioning in these patients.

Specifically, participants with BD and comorbid MS were compared to those without MS in terms of relevant functioning areas (intellectual functioning, sexual functioning, feelings of stigmatization, social withdrawal, household relations, participation in social activities, daily activities and hobbies, initiative-taking, and self-sufficiency); no significant differences were found between 

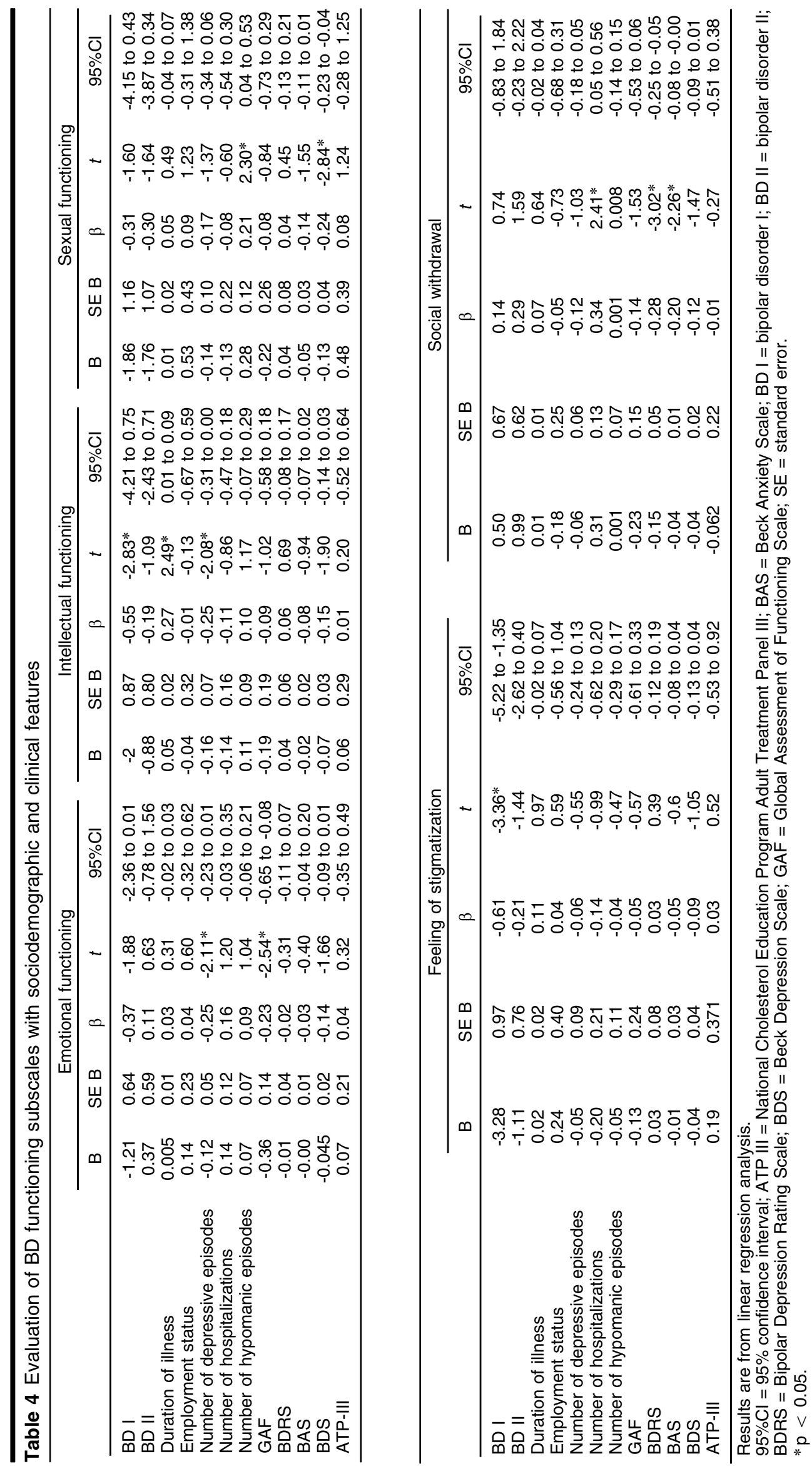


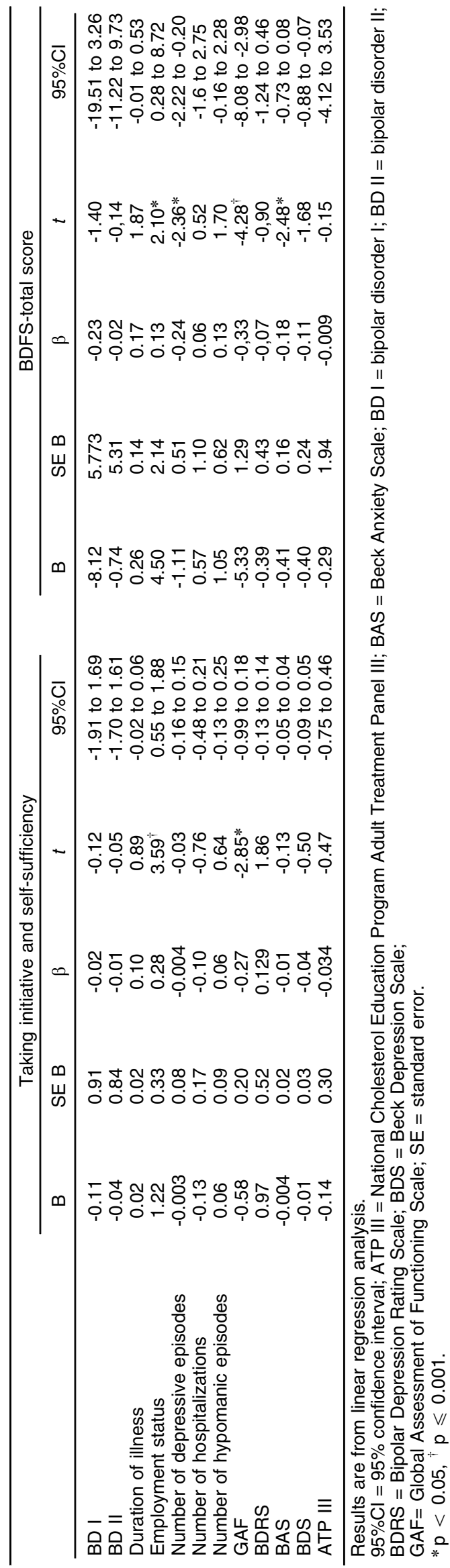


the groups. In a study evaluating the effects of MSrelated lifestyle factors on quality of life and functioning in patients with BD and schizophrenia, no difference was noted in terms of the level of functioning assessed by the GAF. ${ }^{12}$ In another study evaluating the effects of the MS on clinical outcome in BD, MS was associated with previous hospitalizations, severe tardive dyskinesia, poor insight, and poor global functioning. ${ }^{24}$ However, Vancamfort et al. evaluated physical activity levels and functioning in BD patients with $\mathrm{MS}$, and found no significant between-group differences in physical activity or global functioning. 25

In our study, we evaluated the correlation between specific functional areas, clinical features, and MS in bipolar patients in remission. Emotional functioning correlated positively with general functioning levels, and negatively with number of depressive episodes. A previous study comparing patients with $B D$ with healthy controls in terms of their emotional functioning reported no significant difference between the groups. ${ }^{26}$ However, MacQueen et al. reported that the number of depressive episodes had a negative effect on psychosocial functioning. ${ }^{27}$ In our study, patients who had more depressive episodes scored lower in terms of emotional and general functioning, which is consistent with the findings of MacQueen et al. ${ }^{27}$

In our study, domains such as attention, concentration, and memory were assessed in terms of intellectual functioning. There were significant negative correlations of intellectual functioning with number of depressive episodes and being diagnosed with BD I, as well as a positive correlation between intellectual functioning and duration of illness. In terms of cognitive functioning, a study in which BD I and BD II were assessed with the functioning assessment short test (FAST) found lower cognitive performance in BD II than in BD I. However, after controlling for age, subsyndromal depressive symptoms, and number of depressive episodes, this statistical difference between groups disappeared. ${ }^{28}$ Additionally, a study conducted by Simonsen et al. revealed that BD I patients had clinically significant cognitive impairment (in memory and some aspects of executive function) compared to BD II patients. ${ }^{29}$ This may be explained by the fact that bipolar subtypes have different neurocognitive profiles, and that the number of depressive episodes is closely related to neurocognitive impairment.

Sexual functioning (sexual desire, arousal, pleasure) correlated negatively with BDI scores, and positively with number of hypomanic episodes. In a previous study, patients with $\mathrm{BD}$ were found to experience difficulties in achieving sexual desire, arousal, and orgasm compared to healthy controls. ${ }^{30}$ Another study reported a negative correlation between sexual functioning and the duration of illness, residual depressive symptoms, and the number of episodes. ${ }^{31}$ These findings suggest that the consequences of BD should be taken into account, as well as the known adverse effects of medication (e.g., decrease in sexual desire), when considering sexual disability in patients with BD.

There was a significant negative correlation between feelings of stigma and being diagnosed with BD I. It has been reported that patients with a younger age at onset of illness experience greater feelings of stigmatization. In addition, stigmatization has been reported as greater in those with a family history of the disease and those who experience recurrence of the disease in certain seasons. ${ }^{32}$ Perceived stigma is of importance to persons with mental illness, both for how they experience their illness and for its consequences, including on health services utilization. Studies have demonstrated a correlation between stigma and poor functioning in patients with BD. ${ }^{33}$ Considering that early onset, seasonality, and a greater number of lifetime hospitalizations are clinical features of the BD I subtype, our results are in line with the literature.

There was a significant negative correlation of social withdrawal with BDRS and BAS scores. This may be explained by the lower social interaction of patients with subthreshold depressive symptoms and high levels of anxiety. Interestingly, there was a positive correlation between social withdrawal and number of hospitalizations.

Household relations correlated negatively with BDRS scores. Studies conducted in this field have reported that patients with persistent subclinical symptoms - and especially those with residual depressive symptoms are unable to take on family roles, and that their familial role functioning is adversely affected. ${ }^{31}$

As expected, there was a negative correlation between participation in social activities and the number of depressive episodes. In a previous study, interpersonal function correlated with the number of prior episodes of depression but not with number of manic episodes. ${ }^{34}$ Conversely, there were positive correlations of participation in social activities with number of hospitalizations and general functioning level. Consistent with our study results, it has been reported that, as the number of depressive episodes increases, patients avoid entering social environments. ${ }^{35}$

Daily activity and hobbies showed a significant negative correlation with diagnosis of BD II and with number of depressive episodes. Studies conducted in this area have reported that patients with $B D$ II group experience a greater number of depressive episodes, and that patients are less likely to engage in their daily activities and hobbies due to the shorter duration of remission periods in this subtype. ${ }^{36}$ Previous reports also demonstrated that, as the number of depressive episodes and residual depressive symptoms increased, difficulties experienced in functioning areas such as autonomy, occupational involvement, interpersonal relationships, and leisure time increased as well. ${ }^{37}$ Additionally, the positive correlations of daily activity and hobbies with duration of illness and employment status may be explained by patients' getting used to this condition (or accepting it) as the duration of the illness increases.

As expected, initiative-taking correlated positively with employment status and general functioning level. BD patients are known to experience professional and social difficulties even during periods of remission. ${ }^{38}$

Total BDFS scores correlated significantly with employment status, total number of depressive episodes, general functioning level, and BAS scores. The correlation was positive for general functioning and working status 
and negative for BAS scores and total number of depressive episodes.

When subscales were tested for correlation with MS parameters, we found negative correlations of intellectual functioning and participation in social activities with waist circumference and systolic blood pressure. In a study evaluating neurocognitive functions in overweight and obese bipolar patients, there was a weak negative correlation between $\mathrm{BMI}$ and nonverbal memory, and no correlation between BMI and other cognitive domains. ${ }^{39}$ Another study showed a correlation between hypertension and global cognitive dysfunction in remitted BD. ${ }^{40}$ The negative correlation between waist circumference and participation in social activities can be explained by the fact that people with abdominal obesity refrain from participating in social activities due to social attitudes toward obese bodies, but further studies are needed in this regard.

In our study, patients with MS did not differ from those without MS in level of functioning; nevertheless, level of functioning correlated significantly with number of depressive episodes, duration of illness, BDS, BDRS, and BAS total scores, and number of hospitalizations. In this context, persistent subclinical symptoms - and, especially, residual depressive symptoms - may be of great relevance to achieving an adequate level of occupational and social functioning. However, number of episodes, number of hospitalizations, number of suicide attempts, substance use, and comorbidities were all related to psychosocial dysfunction. In conclusion, clinicians should not assume that patients with BD are sufficiently "healed" when they meet conventional "complete remission" criteria. The therapeutic approach should integrate pharmacological and psychosocial interventions, including aspects such as autonomy and social activity and, ultimately, functional recovery.

Some limitations of the present study must be considered. The cross-sectional design, lack of a longitudinal follow-up period, general lack of similar studies in this population, and inclusion only of euthymic cases may reduce the generalizability of the results. Additionally, we have not analyzed the potential effect of polypharmacy on functioning and, consequently, its potential impact on our findings.

In conclusion, it is known that most patients with $\mathrm{BD}$ experience loss of functioning in their social, professional, and interpersonal relationships, even when clinical symptoms are properly controlled. The increasing prevalence of MS in BD due to changes in dietary and habits lifestyle might affect the natural history of the disorder, patient adherence to treatment, and comorbidity profile of BD. In this context, our findings might help clinicians in their clinical judgment during the evaluation and treatment of BD patients with MS. In our study, there was no correlation between the diagnosis of MS and functioning in patients with BD. This may be explained by the fact that clinical variables have a greater impact on functioning than comorbid MS does in this patient population.

Among clinical variables, the number of depressive episodes and subclinical depressive symptoms were the strongest predictors of functioning. In this context, persistent subclinical symptoms - and especially residual depressive symptoms - may be particularly relevant to achieving an adequate level of occupational and social functioning; to reduce disability, these symptoms should be selectively and proactively considered as a therapeutic target.

\section{Disclosure}

The authors report no conflicts of interest.

\section{References}

1 Ferrari AJ, Baxter AJ, Whiteford HA. A systematic review of the global distribution and availability of prevalence data for bipolar disorder J Affect Disord. 2011;134:1-13.

2 Işık E, Işık U, Işık Taner Y. Çocuk, Ergen, Erişkin ve Yaşılılarda Depresif ve Bipolar Bozukluklar. Ankara: Rotatıp Kitapevi; 2013.

3 Salvi V, Albert U, Chiarle A, Soreca I, Bogetto F, Maina G. Metabolic syndrome in Italian patients with bipolar disorder. Gen Hosp Psychiatry. 2008;30:318-23.

4 Alberti KG, Zimmet P, Shaw J. Metabolic syndrome -- a new world-wide definition. A consensus statement from the international diabetes federation. Diabet Med. 2006;23:469-80.

5 de Almeida KM, Moreira CL, Lafer B. Metabolic syndrome and bipolar disorder: what should psychiatrists know? CNS Neurosci Ther. 2012; 18:160-6.

6 Howell JM, Boies K. Champions of technological innovation: the influence of contextual knowledge, role orientation, idea generation, and idea promotion on champion emergence. Leadersh Q. 2004;15: 123-43.

7 Kauer-Sant'Anna M, Bond DJ, Lam RW, Yatham LN. Functional outcomes in first-episode patients with bipolar disorder: a prospective study from the systematic treatment optimization program for early mania project. Compr Psychiatry. 2009;50:1-8.

8 Judd LL, Akiskal HS, Schettler PJ, Coryell W, Endicott J, Maser JD, et al. A prospective investigation of the natural history of the long-term weekly symptomatic status of bipolar II disorder. Arch Gen Psychiatry. 2003;60:261-9.

9 Tohen M, Zarate CA Jr, Hennen J, Khalsa HM, Strakowski SM, Gebre-Medhin P, et al. The McLean-Harvard first-episode mania study: prediction of recovery and first recurrence. Am J Psychiatry. 2003;160:2099-107.

10 Dion GL, Tohen M, Anthony WA, Waternaux CS. Symptoms and functioning of patients with bipolar disorder six months after hospitalization. Hosp Community Psychiatry. 1988;39:652-7.

11 Calkin C, Van de Velde C, Růžičková M, Slaney C, Garnham J, Hajek $\mathrm{T}$, et al. Can body mass index help predict outcome in patients with bipolar disorder? Bipolar Disord. 2009;11:650-6.

12 Malhotra N, Kulhara P, Chakrabarti S, Grover S. Lifestyle related factors \& impact of metabolic syndrome on quality of life, level of functioning \& self-esteem in patients with bipolar disorder \& schizophrenia. Indian J Med Res. 2016;143:434-42.

13 American Psychiatric Association. Diagnostic and Statistical Manual of Mental Disorders, Fifth Edition (DSM-5). Arlington: American Psychiatric Publishing; 2013.

14 Aydemir Ö, Eren I, Savaş H, Kalkan Oguzhanoglu N, Koçal N, Devrimci Ozgüven $\mathrm{H}$, et al. [Development of a questionnaire to assess inter-episode functioning in bipolar disorder: Bipolar Disorder Functioning Questionnaire]. Turk Psikiyatri Der. 2007;18:344-52.

15 Young RC, Biggs JT, Ziegler VE, Meyer DA. A rating scale for mania: reliability, validity and sensitivity. Br J Psychiatry. 1978;133:429-35.

16 Berk M, Malhi GS, Cahill C, Carman AC, Hadzi-Pavlovic D, Hawkins MT, et al. The Bipolar Depression Rating Scale (BDRS): its development, validation and utility. Bipolar Disord. 2007;9:571-9.

17 Batmaz S, Ozdel K, Kocbiyik S, Karadag H. The validity and reliability of the Turkish version of the bipolar depression rating scale. Compr Psychiatry. 2014;55:1448-54.

18 Steer RA, Beck AT. Beck Anxiety Inventory. In: Zalaquett CP, Wood RJ, eds. Evaluating stress: a book of resources. Lanham: Scarecrow Education; 1997. p. 23-40. 
19 Ulusoy M, Sahin NH, Erkmen H. Turkish version of the Beck anxiety inventory: psychometric properties. J Cogn Psychother. 1998;12:163.

20 Beck AT, Steer RA, Brown GK. Beck Depression Inventory-Second Edition (BDI-II). San Antonio: Psychological Corporation; 1996.

21 Hisli N. [A study on the validity of Beck depression inventory]. Turk J Psychol. 1988;6:118-23.

22 Endicott J, Spitzer RL, Fleiss JL, Cohen J. The global assessment scale: A procedure for measuring overall severity of psychiatric disturbance. Arch Gen Psychiatry. 1976;33:766-71.

23 Expert Panel on Detection, Evaluation, and Treatment of High Blood Cholesterol in Adults. Executive summary of the third report of the national cholesterol education program (NCEP) expert panel on detection, evaluation, and treatment of high blood cholesterol in adults (Adult Treatment Panel III). JAMA. 2001;285:2486-97.

24 Bai YM, Li CT, Tsai SJ, Tu PC, Chen MH, Su TP. Metabolic syndrome and adverse clinical outcomes in patients with bipolar disorder. BMC Psychiatry. 2016;16:448.

25 Vancampfort D, Sienaert P, Wyckaert S, De Hert M, Stubbs B, Kinyanda $E$, et al. The metabolic syndrome is associated with selfreported physical complaints in patients with bipolar disorder. Psychiatr Danub. 2016;28:139-45.

26 Tiğli Filizer A, Cerit C, Tüzün B, Aker AT. Social aspect of functioning deteriorates more than individual aspect in patients with remitted bipolar disorder. Noro Psikiyatr Ars. 2016;53:158-62.

27 MacQueen GM, Young LT, Robb JC, Marriott M, Cooke RG, Joffe RT. Effect of number of episodes on wellbeing and functioning of patients with bipolar disorder. Acta Psychiatr Scand. 2000;101:374-81.

28 Rosa A, González-Ortega I, González-Pinto A, Echeburua E, Comes M, Martínez-Àran A, et al. One-year psychosocial functioning in patients in the early vs. late stage of bipolar disorder. Acta Psychiatr Scand. 2012;125:335-41.

29 Simonsen C, Sundet K, Vaskinn A, Birkenaes AB, Engh JA, Hansen $\mathrm{CF}$, et al. Neurocognitive profiles in bipolar I and bipolar II disorder: differences in pattern and magnitude of dysfunction. Bipolar Disord. 2008;10:245-55.
30 Dell'Osso L, Carmassi C, Del Debbio A, Catena Dell'Osso M, Bianchi $C$, da Pozzo E, et al. Brain-derived neurotrophic factor plasma levels in patients suffering from post-traumatic stress disorder. Prog Neuropsychopharmacol Biol Psychiatry. 2009;33:899-902.

31 Canbazoğlu M, Akkaya C, Cangür Ş, Kırlı S. The effect of residual symptoms on clinical characteristics and functioning of patients with bipolar disorder in remission. Anadolu Psikiyatri Derg. 2013;14: 228-36.

32 Üstündağ MF, Kesebir S. İki uçlu bozuklukta içselleştirilmiş damgalanma: Klinik özellikler, yaşam kalitesi ve tedaviye uyum ile ilişkisi. Turk Psikiyatri Dergisi. 2013;24:231-9.

33 Vázquez GH, Kapczinski F, Magalhaes PV, Córdoba R, Lopez Jaramillo C, Rosa A, et al. Stigma and functioning in patients with bipolar disorder. J Affect Disord. 2011;130:323-7.

34 Gitlin MJ, Swendsen J, Heller TL, Hammen C. Relapse and impairment in bipolar disorder. Am J Psychiatry. 1995;152:1635-40.

35 Aydemir O. Functioning and quality of life in bipolar disorder. Dusunen Adam. 2016;29:1.

36 İlhan RS, Şentürk Cankorur V. Bipolar Tip II Bozuklukta Ötimik Dönemde İşlevselliğin Klinik ve Bilişsel Yordayıcıları. Turk Psikiyatri Derg. 2015;26:13-20.

37 Rosa AR, Reinares M, Franco C, Comes M, Torrent C, Sánchez-Moreno J, et al. Clinical predictors of functional outcome of bipolar patients in remission. Bipolar Disord. 2009;11:401-9.

38 Bonnín CM, Martínez-Arán A, Torrent C, Pacchiarotti I, Rosa AR, Franco $\mathrm{C}$, et al. Clinical and neurocognitive predictors of functional outcome in bipolar euthymic patients: a long-term, follow-up study. J Affect Disord. 2010;121:156-60.

39 Silveira LE, Kozicky JM, Muralidharan K, Bücker J, Torres IJ, Bond DJ, et al. Neurocognitive functioning in overweight and obese patients with bipolar disorder: data from the Systematic Treatment Optimization Program for Early Mania (STOP-EM). Can J Psychiatry. 2014:59:639-48.

40 Hubenak J, Tuma I, Bazant J. Association of arterial hypertension and cognitive impairment in euthymic bipolar disorder. Neuro Endocrinol Lett. 2015;36:294-300. 